\title{
The effect of surface roughness of the impeller to the performance of pump as turbine pico power plant
}

\author{
D. L. Zariatin ${ }^{1 * *}$, Dwi Rahmalina ${ }^{1}$, Eko Prasetyo ${ }^{1}$, A. Suwandi ${ }^{1}$, M. Sumardi ${ }^{1}$ \\ ${ }^{1}$ Department of Mechanical Engineering, Universitas Pancasila \\ Jln. Srengseng Sawah, Jakarta Indonesia \\ Phone: +6282124588227 Fax: +62217270128 \\ *Email: dedeliazariatin@univpancasila.ac.id
}

\begin{abstract}
Pump as Turbine (PAT) is one of a hydropower plant that applies a pump with a reversed flow, working as a turbine to generate electrical power. It has the advantages of low-cost, widely available in the market and user-friendly. However, like other hydropower plants, PAT technology has low performance in term of power output. The impeller surface roughness is one of critical aspect, which influences PAT performance because poor surface roughness causes losses and cavitation. The objective of the research is to increase the PAT performance by improving the quality of the surface roughness and validate by the experimental tests. A low-cost and customize hand grinding process was applied to produce five impellers with three different levels of surface roughness (average surface roughness of $0.16 \mu \mathrm{m}, 0.24 \mu \mathrm{m}$, and $0.40 \mu \mathrm{m}$ ), an edge rounded impeller, and a varnish lacquer coated impeller. All of the impellers undergo performance testing. The performance of the original impeller (without modification) used as a comparison. The experiment result shows that an impeller with a lower surface roughness (lower Ra number) has a higher performance. An impeller with an average surface roughness of $0.16 \mu \mathrm{m}$ improved $10.9 \%$ of its initial performance. Additional edge rounding for a $0.16 \mu \mathrm{m}$ surface roughness impeller would improve its performance by $13.1 \%$. The optimum turbine efficiency of $15.45 \%$ was achieveable by implementing an impeller with the lowest surface roughness.
\end{abstract}

Keywords: Pump as turbine; surface roughness; impeller; impeller rounding

\section{INTRODUCTION}

Pump as turbine or known as PAT is one of an alternative green power plant that can be applied easily in a remote or rural area. Most of PAT micro or pico hydropower plant used a centrifugal pump to generate power. Generally, a centrifugal pump is designed to use electrical energy to deliver water flow, but in a PAT power plant, the water flows rotate the impeller and rotor shaft to generate electrical energy. Although the commercial pump is not designed to convert the potential energy of water into electrical energy, however, several research articles have revealed that a commercial pump available in the market can be used as a turbine and generate electricity [1-5]. PAT has many advantages such as low cost, less complexity, mass production, availability for a wide range of heads and flows, short delivery 
time, available in a large number of standard sizes, ease of availability of a spare part, easy installation, etc. $[1,6,7]$. Nevertheless, the PAT power generation efficiency of the pump as turbine technology is still low.

There are some losses in the PAT system, including hydraulic losses. Yang et al. stated that the optimization of the PAT should mainly focus on the impeller [8]. Many studies performed in order to investigate the application of the PAT and how to increase the turbine efficiency through impeller modification. Deraskhshan et al. [9] increased the turbine efficiency by redesigned the impeller using a gradient-based optimization algorithm coupled by a 3D Navier-Stokes flow solver. Another modification to impeller was done by rounding the blades' leading edges and hub/shroud interface in turbine mode. The experimental result shows that optimized impeller increased the power and the efficiency up to $14.8 \%$ and $2.9 \%$, respectively. Meanwhile, the rounding of optimized impeller increased the power and the efficiency up to $36.1 \%$ and $5.5 \%$, respectively.

Yang et al. [10] investigated the effect of impeller trimming on efficiency. As the impellers trimmed, it changes the geometrical parameters of diameter, inlet width, blade wrap angle, and blade inlet angle. Yang et al. [8] also investigated the effect of wrap angle modification to PAT performance. Those researchers found that hydraulic losses reduced significantly along with the decrease of the blade wrap angle.

Meanwhile, Jain et al. [11] modified the blade by trimming and rounding for three different impeller diameter. The recommendation was to run PAT at 1100 RPM with $10 \%$ trimmed-blade rounded impeller. Another impeller rounding investigated by Singh and Nestmann [12] and Suarda et al. [13]. The research found that the impeller rounding improved the Best Efficiency Point (BEP) efficiency. Impeller rounding is a recommended modification to optimize the PAT impeller.

In the previous research [14] shows that a modified impeller with six number of blades with a better surface roughness $(\mathrm{Ra}=0.28 \mu \mathrm{m})$ generated more power than the original impeller that has five number of blades and $\mathrm{Ra}=12.5 \mu \mathrm{m}$. The modified impellers were manufactured by Numerical Controller (NC) milling machine. The experimental result showed that the power generated by the modified impeller is 27.14 Watt, which improve-able approximately 1.5 times than the original impeller.

According to Varley [15], the surface roughness is the most critical factor that controls the amount of hydraulic flow and friction losses in the radial flow pump impeller. In an ideal liquid, flow through the boundary has a uniform velocity distribution. Whereas the actual liquid, the effect of viscosity, speed close to the boundary region experienced a slowdown and the speed limit field is zero. A layer of liquid water near the boundary where the influence of the dominant viscosity is called the boundary layer. The concept of the sublayer in a laminar boundary layer in a turbulent flow can be used to explain the behavior of surface roughness. Poullikkas [16] stated that the disk friction coefficient increases by the disk roughness. The disk friction is considered as loses in the operating pump. Kaewnai [17] used Computational Fluid Dynamic (CFD) to predict the performance of the radial flow type impeller of centrifugal pumps. The performance parameters obtained from the models show that losses in the impeller increase with the increase of surface roughness.

The poor surface roughness of hydro turbine components such as impeller blade, guide vane, etc. could cause cavity and affect the hydro turbine performance [18]. Higher roughness on the surface generally enhances the cavitation intensity and erosion of the solid surface. The cavitation would damage the hydro turbine installation. To overcome the 
problem, Gülich [19] proposed a procedure to predict the effect of roughness on the centrifugal pump efficiency and the disk friction losses [20]. The impeller geometry modification had been proposed and proved by several researchers [7-15] as a best practice to improve the PAT performance, yet still few researches investigated in-depth about the effect of surface roughness toward PAT performance. The objective of this research is to improve PAT performance by modifying the impeller surface roughness.

\section{EXPERIMENTAL SETUP}

Generally, the impeller of a centrifugal pump available in the market is manufactured by a casting process with a high level of surface roughness $(\mathrm{Ra})$. The casting process than followed by machining processes such as cutting, turning, and grinding. The machining process is used to cut the gating system, riser and to smooth the outer sides of the impeller. Due to the limitation of machine tools working range, the inner side of the impeller has a significant difference in surface roughness compared to the outer sides of the impeller. Figure 1 shows the surface condition of the original impeller before the modification, where the inner side of the impeller has a rougher surface than the outer side.

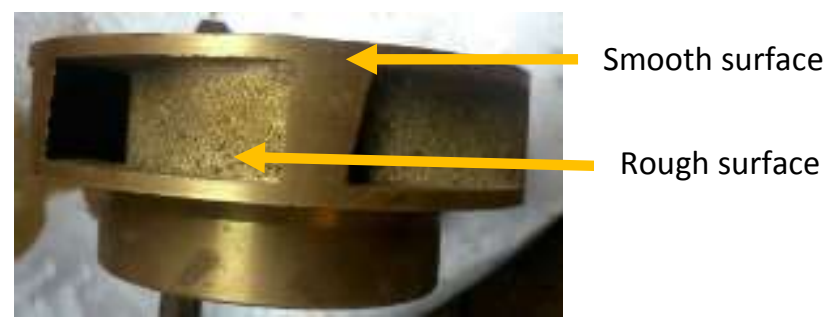

Figure 1. The surface condition of the original impeller

The impellers made of brass that used in this experiment were acquired from the market. It has six numbers of blades, as shown in Figure 2 (a). In order to identify the impeller dimension, one of the impeller was cut and measured by Brown and Sharpe Global Performance 5.7.5 Coordinate Measuring Machine.

The impeller diameter is $124 \mathrm{~mm}$, with an overall thickness of $51 \mathrm{~mm}$. The blade thickness varies between $3.25 \mathrm{~mm}$ to $9.25 \mathrm{~mm}$. Meanwhile, the outer diameter of the impeller shaft is $14 \mathrm{~mm}$. Figure 2 (b) shows the impeller dimension. The inner surface roughness of the original impeller (un-modified impeller) was measured by a Surface Roughness Comparator Plates as shown in Figure 2 (a) because the roughness of the original impeller is above the measurement range of the digital surface roughness tester. 


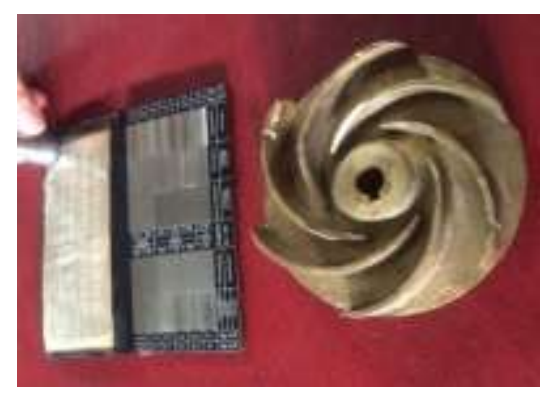

(a)
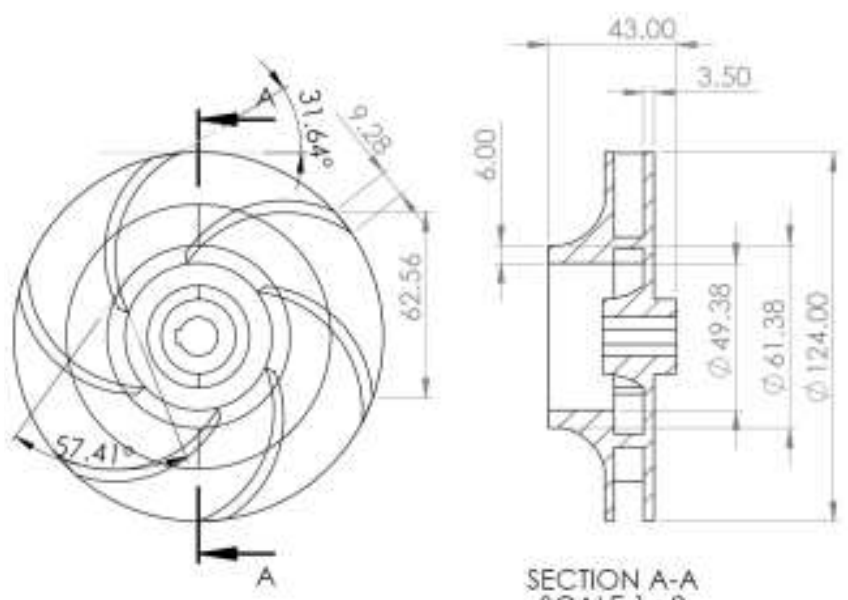

SECTION A-A

(b)

Figure 2. (a) The cross-sectional view of the impeller, (b) impeller dimension

The hand grinding process with a different level of grinding tools roughness was used to smooth the inner surface of the impeller and to round the impeller edge. The hand grinding process is economical and performed by an inexperienced workman. The roughness of modified impellers was measured by the Digital Surface Roughness Tester SJ-201P, as shown in Figure 3. The SJ-201P was set with a length of measurement of $0.8 \times 5 \mathrm{~mm}$, drive speed of $0.2 \mathrm{~mm} / \mathrm{s}$ and a sample length of $2.5 \mathrm{~mm}$. The inner surface of each blade was measured and averaged as listed in Table 1.

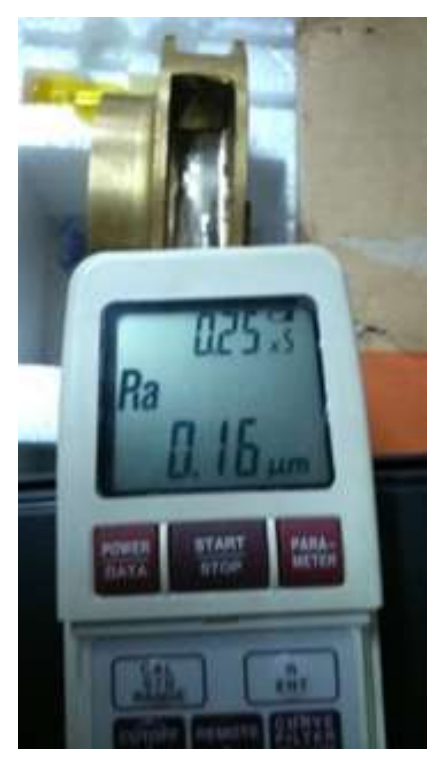

Figure 3. Surface roughness measurement 
Table 1. Impeller condition

\begin{tabular}{|c|c|c|}
\hline No. & Impeller Figure & Condition \\
\hline 1 & & Original impeller, Average $\mathrm{Ra}=12 \mu \mathrm{m}$ \\
\hline 2 & & Average $\mathrm{Ra}=0.16 \mu \mathrm{m}$ \\
\hline 3 & & Average $\mathrm{Ra}=0.24 \mu \mathrm{m}$ \\
\hline 4 & & Average $\mathrm{Ra}=0.40 \mu \mathrm{m}$ \\
\hline 5 & & Average $\mathrm{Ra}=0.16 \mu \mathrm{m}$, varnish lacquer coating \\
\hline 6 & & $\begin{array}{c}\text { Average } \mathrm{Ra}=0.16 \mu \mathrm{m} \text {, edge rounding radius }= \\
0.5 \mathrm{~mm}\end{array}$ \\
\hline
\end{tabular}

After the modification process, the impellers were installed to a Morris MFM 130A centrifugal pump and tested by using a Laboratory Scale PAT test facility as shown in Figure 4(a) and (b) [21]. Water (assumed as $\mathrm{H}_{2} \mathrm{O}$ ) flowed from a reservoir tank made from PVC and placed 3.7 meters height above the ground. A commercial centrifugal pump placed 3 meters below the tank and applied as a PAT to generate electric power. The inlet flow rate to the PAT adjusted by a valve as shown in Figure 4(c). According to the pump specification, the maximum water discharge $(\mathrm{Q})$ of the pump is $60 \mathrm{~m}^{3} / \mathrm{h}$ or $1000 \mathrm{~L} / \mathrm{min}$ with a maximum head of $12 \mathrm{~m}$. However, due to the space constraint in the laboratory, the water is flowed down only from 3 meter above the PAT.

The experiment procedure was adapted from SNI 8277:2016 [22] and previous research $[13,14]$. The rotational velocity of the impeller measured by using a Krisbow KW06-302 hand tachometer with auto range mode, the accuracy of $0,05 \%$, and the sampling 
time of $0,8 \mathrm{~s}$ (over $60 \mathrm{RPM}$ ). The inlet and outlet pressure, flow rate and water temperature were measured by an integrated system that consists of HK 1100C hydraulic pressure sensor, Hall effect Sea water flow sensor, and DS18B20 waterproof temperature sensor that controlled by Arduino UNO. Meanwhile, the electric power generated by PAT facility measured by a Krisbow KW06-286 digital clamp meter with a resolution to $1 \mathrm{~mA}$ DC/AC in a range of $0 \mathrm{~A} \sim 400 \mathrm{~A}$ and accuracy of $\pm 0.1 \%$.

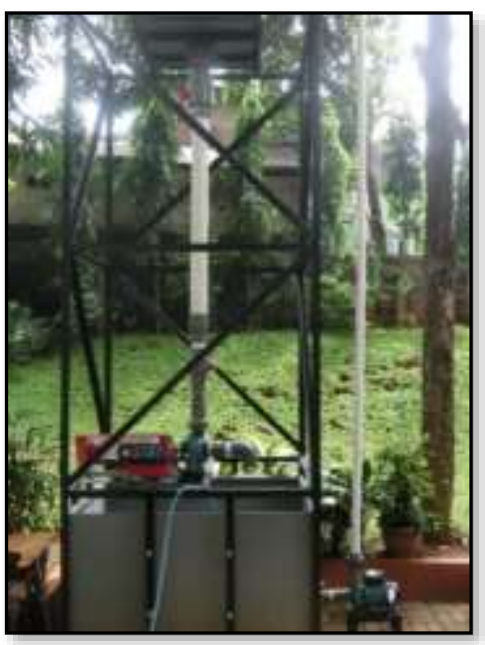

(a)

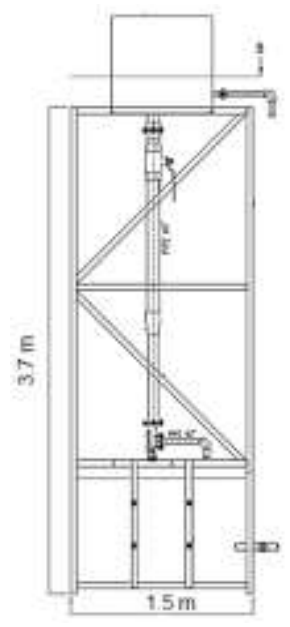

(b)

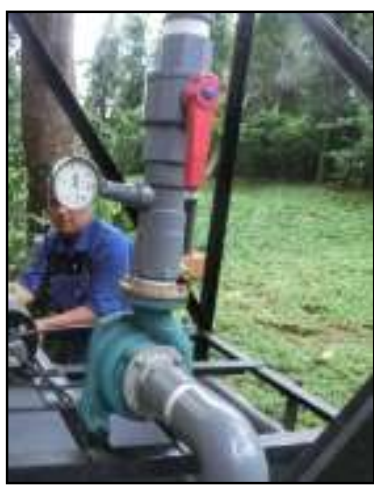

(c)

Figure 4. Test Facility

\section{RESULT AND DISCUSSION}

The result of the experiments for each impeller list in Table 2. The formula to calculates the turbine efficiency:

$$
\eta=\frac{P}{1000 \cdot \gamma \cdot Q \cdot H}
$$

Where P is the electric power generated by PAT (Watt) facility, measured on its generator, $\mathrm{Q}$ is the water flow rate $(\mathrm{L} / \mathrm{s})$. $\mathrm{H}$ is the head of waterfalls which is $3.7 \mathrm{~m}$. $\gamma$ is a specific weight of water at a temperature of $30^{\circ} \mathrm{C}$, which is $9,765 \mathrm{~N} / \mathrm{m}^{2}$.

As a comparison of the current research to the previous research performed by Suarda et al. [13] that conducted the same modification blade rounding regardless the impeller surface roughness, the current research generates more power up to 43\%. Suarda et al. [13] stated that the optimum power generated is 79.36 Watt with the flow-rate and head of 0.00199 $\mathrm{m}^{3} / \mathrm{s}(119.4 \mathrm{~L} / \mathrm{s})$ and $13 \mathrm{~m}$, respectively. Figure 5 plots the effect of surface roughness to the flow-rate and the power generated. It shows that the highest power generated achieved by using a rounded impeller with the average surface roughness of $0.16 \mu \mathrm{m}$. Impeller with an average surface roughness of $12 \mu \mathrm{m}$ generated the lowest power compare to others. It can be concluded that a simple and economical modification of the impeller by improving the surface roughness increase the electric power generated. 
Table 2. The Experiment result

\begin{tabular}{ccccc}
\hline Impeller & $\mathbf{N}(\mathbf{R P M})$ & $\mathbf{Q}, \mathbf{L} / \mathbf{s}$ & $\mathbf{P}(\mathbf{W})$ & $\boldsymbol{\eta} \mathbf{( \% )}$ \\
\hline & 124 & 1.78 & 4 & 6.21 \\
Original Impeller, & 864 & 13.17 & 53 & 11.14 \\
$\mathrm{Ra}=12 \mu \mathrm{m}$ & 1,318 & 19.45 & 97 & 13.80 \\
& 1,487 & 19.85 & 101 & 14.08 \\
\hline & 125 & 1.62 & 6.0 & 10.25 \\
Average $\mathrm{Ra}=0.4 \mu \mathrm{m}$ & 963 & 12.56 & 64.0 & 14.10 \\
& 1,389 & 18.23 & 98.0 & 14.88 \\
& 1,495 & 19.85 & 109.0 & 15.20 \\
\hline & 128 & 2.03 & 8.0 & 10.93 \\
Average $\mathrm{Ra}=0.24 \mu \mathrm{m}$ & 1,000 & 13.17 & 70.6 & 14.84 \\
& 1,482 & 19.45 & 106.0 & 15.09 \\
& 1,503 & 19.85 & 110.3 & 15.38 \\
\hline & 130 & 1.62 & 8.0 & 13.66 \\
Average $\mathrm{Ra}=0.16 \mu \mathrm{m}$ & 1,006 & 13.37 & 74.0 & 15.32 \\
& 1,489 & 19.65 & 109.0 & 15.35 \\
& 1,532 & 20.06 & 112.0 & 15.46 \\
\hline \multirow{2}{*}{ Average $\mathrm{Ra}=0.16 \mu \mathrm{m}}$, & 134 & 1.82 & 7.0 & 10.63 \\
Varnish lacquer & 1,020 & 13.37 & 65.6 & 13.58 \\
coating & 1,489 & 18.23 & 100.3 & 15.23 \\
& 1,557 & 19.69 & 109.9 & 15.45 \\
\hline \multirow{2}{*}{ Average $\mathrm{Ra}=0.16 \mu \mathrm{m}}$, & 127 & 1.82 & 9.0 & 13.66 \\
rounding radius $=0.5$ & 976 & 13.78 & 74.8 & 15.03 \\
$\mathrm{~mm}$ & 1,394 & 19.65 & 109.2 & 15.38 \\
& 1,498 & 20.46 & 114.2 & 15.45 \\
\hline
\end{tabular}

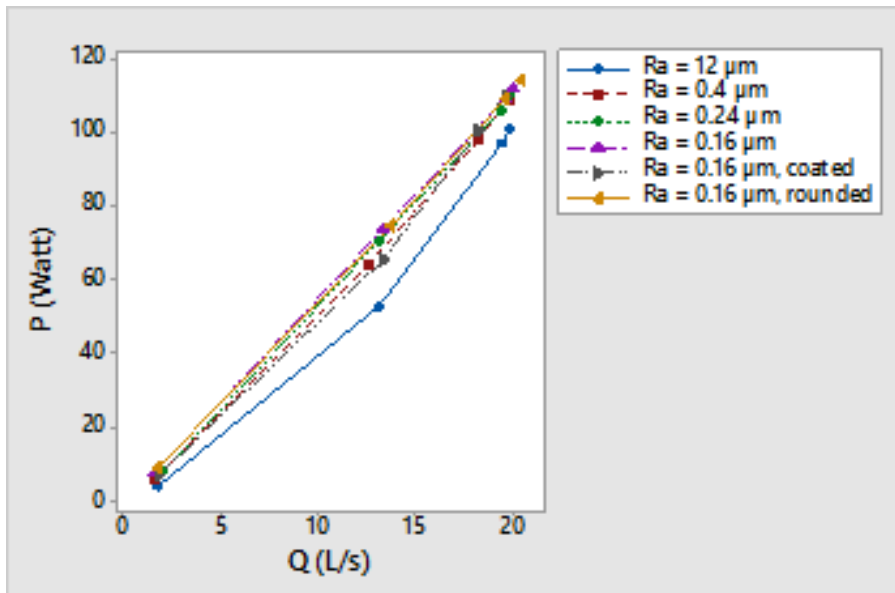

Figure 5. The Power Generated

The performance improvement by surface modification for the maximum flow-rate is listed in Table 3 and presented in Figure 6. It shows that at the highest flow-rate, the performance 
improved up to $13.1 \%$, was achieved by improving the surface roughness to $0.16 \mu \mathrm{m}$ and rounding the impeller tip with a radius of $0.5 \mathrm{~mm}$.

Table 3. Performance Improvement of Impeller Modification

\begin{tabular}{cccc}
\hline No & Impeller Condition & $\mathrm{P}(\mathrm{W})$ & Performance Improvement \\
\hline 1 & Original Impeller, & 101 & Initial \\
& Average $\mathrm{Ra}=12 \mu \mathrm{m}$ & 109 & $7.9 \%$ \\
2 & Average $\mathrm{Ra}=0.40 \mu \mathrm{m}$ & 110.3 & $9.2 \%$ \\
3 & Average $\mathrm{Ra}=0.24 \mu \mathrm{m}$ & 112 & $10.9 \%$ \\
4 & Average $\mathrm{Ra}=0.16 \mu \mathrm{m}$ & 109.9 & $8.8 \%$ \\
5 & Average $\mathrm{Ra}=0.16 \mu \mathrm{m}$, coated & 114.2 & $13.1 \%$ \\
6 & Average $\mathrm{Ra}=0.16 \mu \mathrm{m}$, rounded & 11.2 & \\
\hline
\end{tabular}

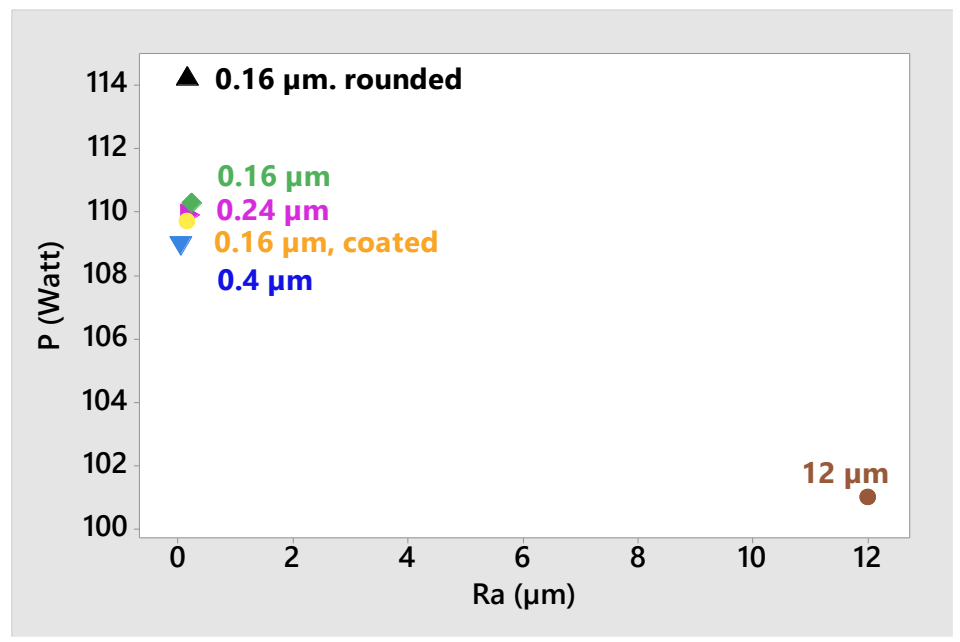

Figure 6. Power Generated for each Impeller

Figure 7 illustrated the turbine efficiency of each impeller. Meanwhile, Figure 8 shows the turbine efficiency of each impeller at the maximum flow-rate. It shows that the most efficient turbine was the impeller with an average surface roughness of $0.16 \mu \mathrm{m}$. The turbine efficiency differences for rounded and coated impeller with a surface roughness of $0.16 \mu \mathrm{m}$ was only $\pm 0.02 \%$ at its maximum flow-rate. However, the coated impeller shows lower efficiency when it operated in lower flow-rate. Meanwhile, the lowest turbine efficiency is when using an impeller with $12 \mu \mathrm{m}$ of surface roughness. 


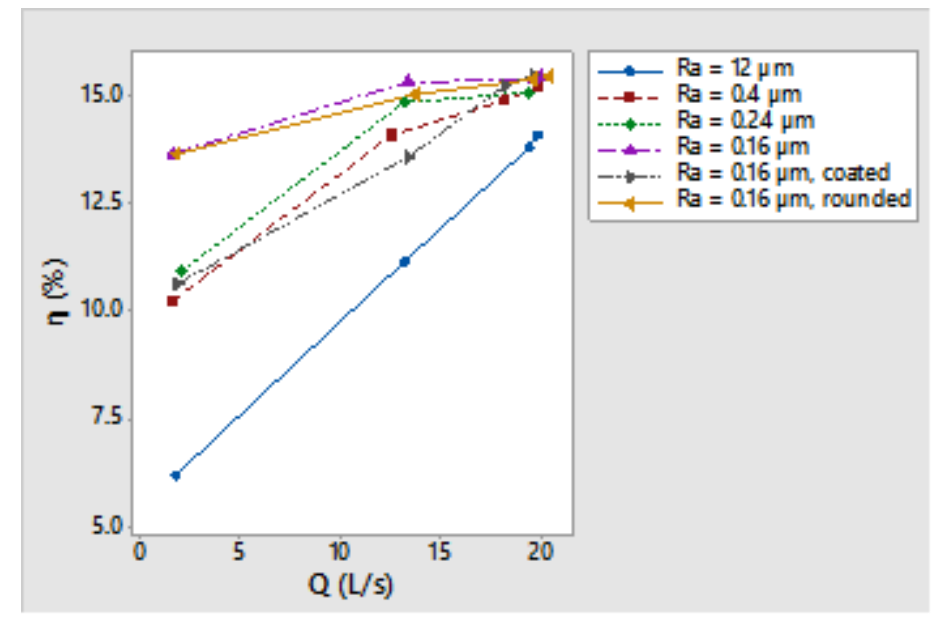

Figure 7. Turbine Efficiency

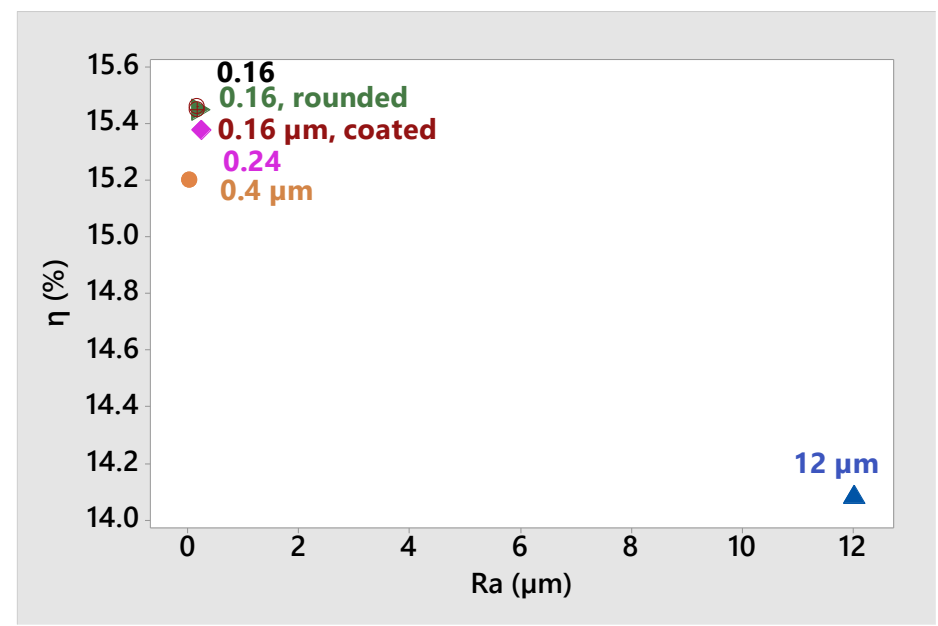

Figure 8. The Turbine Efficiency

\section{CONCLUSION}

Based on the experimental results, it can be concluded that a simple modification by using a hand grinding was improving the surface roughness quality, from $12 \mu \mathrm{m}$ to $0.4 \mu \mathrm{m}, 0.24 \mu \mathrm{m}$, and $0.16 \mu \mathrm{m}$. The improvement of the surface quality increases the electric power generated, up to $13.1 \%$. The turbine efficiency improves as the impeller surface roughness improved. The experimental result shows that rounding the edges of the impeller with a surface roughness of $0.16 \mu \mathrm{m}$ generated more power, approximately $2.2 \%$ of the un-rounded impeller. 


\section{ACKNOWLEDGMENT}

This research funded by The Ministry of Research Technology and Higher Education of Indonesia in a grant scheme of Hibah Tim Pascasarjana.

\section{REFERENCES}

[1] A. Carravetta, S. D. Houreh, and H. M. Ramos. Pumps as Turbines. Springer;2018.

[2] D. A. Himawanto, D. D. D. P. Tjahjana, and Hantarum. 2016. Experimental study on optimization of curvature blade impeller pump as turbine which functioned as power plant picohydro. International Conference on Engineering, Science and Nanotechnology 2016 (ICESNANO 2016) AIP Conference Proceeding 1788.: 030008 1-7;2016.

[3] N. Raman, K. P. Hussein and B. FooAn experimental investigation of pump as turbine for micro hydro application. 4th International Conference on Energy and Environment 2013 (ICEE 2013) - IOP Conf. Series: Earth and Environmental Science 16: 012064 1-4; 2013.

[4] H. Nautiyal, Varun, A. Kumar, and S. Yadav. Experimental Investigation of Centrifugal Pump Working as Turbine for Small Hydropower Systems. Energy Science and Technology 2011; 1: 79-86.

[5] J. Fernández, E. Blanco, J. Parrondo and M. T. Stickland. Performance of a centrifugal pump running in inverse mode. Proceedings of the Institution of Mechanical Engineers, Part A: Journal of Power and Energy 2004; 218: 265-271.

[6] S. V. Jain and R. N. Patel. Investigation on pump running in turbine mode: A review of the state-of-the-art. Renewable and Sustainable Energy Reviews 2014; 30: 841868.

[7] A. Elbratran, O. Yaakob, Y. Ahmed and H. Shabara.. Operation, performance and economic analysis of low head micro-hydropower turbines for rural and remote areas: A review. Renewable and Sustainable Energy Reviews 2015; 43: 40-50.

[8] S.-S. Yang, F.-Y. Kong, C. Hao, and X.-H. Su.. Effects of blade wrap angle influencing a pump as turbine. Journal of Fluids Engineering 2012;134 (061102): 18.

[9] S. Derakhshan, B. Mohammadi and A. Nourbakhsh.. Efficiency Improvement of Centrifugal Reverse Pumps. Journal of Fluids Engineering 2009;131(021103); 1-9.

[10] Y. Sun-Sheng, K. Fan-Yu, J. Wan-Ming and Q. Xiao-Yun. Effects of Impeller Trimming Influencing Pump as Turbine. Computers \& Fluids 2012; 67: 72-78.

[11] S. V. Jain, A. Swarnkar, K. H. Motwani and R. N. Patel. Effects of impeller diameter and rotational speed on performance of pump running in turbine mode. Energy Conversion and Management 2015. 89: 808-824.

[12] P. Singh and F. Nestmann. Internal hydraulic analysis of impeller rounding in centrifugal pumps as turbines. Experimental Thermal and Fluid Science 2011; 35: 121-134. 
[13] M. Suarda, N. Suarnadwipa, and W. B. Adyana. Experimental Work on Modification of Impeller Tips of a Centrifugal Pumps as a Turbine. The 2nd Joint International Conference on Sustainable Energy and Environment (SEE 2006). B-008 (O): 1-5; 2006.

[14] D. Zariatin, S. Kumbarasari, D. Rahmalina. The Performance of Pump as Turbine with Machined Impellers. The 2nd International Joint Conference on Advanced Engineering and Technology (IJCAET 2017) and International Symposium on Advanced Mechanical and Power Engineering (ISAMPE 2017) MATEC Web Conference 2017;159 (02024): 1-6;.

[15] F. Varle Y. Effects of Impeller design and surface roughness on the performance of centrifugal pumps. The proceedings of the Institution of Mechanical Engineers 1961; 175: 955 - 989.

[16] A. Poullikkas. Surface roughness effect on induced flow and frictional resistance of enclosed rotating disks. Journal of Fluids Engineering1995;117: 526 - 528.

[17] S. Kaewnai, M. Chamaoot, and S. Wongwises. Predicting performance of radial flow type impeller of centrifugal pump using CFD. Journal of Mechanical Science and Technology 2009; 23: 1620 - 1627.

[18] R. Singh, S. Tiwari, S. K. Mishra. Cavitation Erosion in Hydraulic Turbine Components and Mitigation by Coatings: Current Status and Future Needs. Journal of Materials Engineering and Performance 2012;21:1539-1551.

[19] J. Gülich. Effect of Reynolds Number and Surface Roughness on the Efficiency of Centrifugal Pumps. Journal of Fluids Engineering 2003; 125: 670-679.

[20] J. Gülich.. Disk friction losses of closed turbomachine impellers. Forschung im Ingenieurwesen 2003; 68: 87-95.

[21] D. L. Zariatin, D. Rhakasywi, F. Ade and A. Setyo. Design of Pump as Turbine Experimental Test Facility. International Conference on Mechanical. Aeronautical and Automotive Engineering (ICMAA 2017) MATEC Web of Conferences 108 (04014): 1-4; 2017.

[22] S. N. Indonesia, SNI 8277: Panduan komisioning pengkit listrik tenaga mikro hidro (PLTMH) kapasitas hingga 100 kW. Badan Standarisasi Nasional, BSN;2016. 